\title{
Hypoxia induces inflammatory microenvironment by priming specific macrophage polarization and modifies LSC behaviour via VEGF-HIF1a signalling
}

\author{
Mingyan Jiang ${ }^{1,2}$, Guoqian He ${ }^{1,2}$, Jialing Wang ${ }^{1}$, Xia Guo ${ }^{1,2}$, Ziyi Zhao ${ }^{3}$, Ju Gao $^{1,2}$ \\ ${ }^{1}$ Department of Pediatric Hematology and Oncology, West China Second University Hospital of Sichuan University, Chengdu, China; ${ }^{2}$ Key \\ Laboratory of Birth Defects and Related Diseases of Women and Children (Sichuan University), Ministry of Education, Chengdu, China; ${ }^{3}$ Hospital \\ of Chengdu University of Traditional Chinese Medicine, Chengdu, China \\ Contributions: (I) Conception and design: Z Zhao, J Gao; (II) Administrative support: M Jiang, Z Zhao; (III) Provision of study materials or patients: \\ M Jiang, J Wang, G He; (IV) Collection and assembly of data: M Jiang, Z Zhao; (V) Data analysis and interpretation: G He, X Guo; (VI) Manuscript \\ writing: All authors; (VII) Final approval of manuscript: All authors. \\ Correspondence to: Ziyi Zhao. Hospital of Chengdu University of Traditional Chinese Medicine, No. 39, Shi-er-qiao Road, Jinniu District, Chengdu, \\ 610000, China. Email: zhaoziyi@cdutcm.edu.cn; Ju Gao. Department of Pediatric Hematology and Oncology, West China Second University \\ Hospital of Sichuan University, No.20, Section 3, Ren Min Nan Lu, Chengdu, 610041, China. Email: gaoju651220@126.com.
}

Background: Leukemia stem cells (LSCs) play pivotal roles in leukemogenesis, and are closely implicated in leukemia relapse and chemoresistance. LSCs are tightly modulated by hypoxic exposure and macrophageconditioned microenvironment. Nevertheless, the impacts on the biology of LSCs imposed by the interaction of hypoxia and macrophage polarization remain elusive.

Methods: In the study, LSCs characterized by CD34+CD38- immunophenotype sorted from KG1 $\alpha$ and primary AML cells were employed as in vitro and ex vivo cell models. mRNA and protein expressions of cytokine/chemokine of cells under normoxic and hypoxic conditions were determined by RT-PCR and western blot. Macrophage polarization, cell cycle and apoptosis were determined by flowcytometry. Cell viability was assayed by CCK-8.

Results: Macrophages preferentially presented with M2 polarization phenotype characterized by upregulated VEGF and CCL17 cytokine/chemokine profile, when stimulated by specific set of cytokines under hypoxic exposure, and induced an anti-inflammatory microenvironment. LSCs exhibited significantly increased cell viability, colony-forming capacity and chemoresistance when co-incubated in hypoxic conditioned medium (H-CM) primed by polarized M1 macrophages. VEGF expression was upregulated in LSCs which in turn activated survivin expression. VEGF-mediated upregulation of survivin could be abolished by inhibition of VEGF receptor, but not blocked by survivin-targeting siRNA. In addition, survivin upregulation exerted antiapoptotic effects and was associated with increased chemoresistance. Finally, VEGF mediated transcriptional induction of HIF- $1 \alpha$ of LSCs coincubated in H-CM, and HIF-1 $\alpha$ induction in turn enhanced chemoresistance and reduced cell apoptosis.

Conclusions: To our best knowledge, this is the first study that focus to explore molecule players and interacting signal pathways regulating LSC biology under hypoxic exposure. It reveals that hypoxia preferentially skew macrophage M2 polarization with specific cytokine profile and proinflammatory microenvironment, which impacts malignant behavior of LSCs. VEGF-HIF-1 $\alpha$ interaction is closely implicated in sustaining LSCs survival under hypoxic exposure and might be of potential target of novel therapy.

Keywords: Acute myeloid leukemia (AML); leukemia stem cells (LSCs); vascular endothelial growth factor (VEGF); chemoresistance; hypoxia-inducible factor $1 \alpha(\mathrm{HIF}-1 \alpha)$

Submitted Mar 05, 2021. Accepted for publication Jun 10, 2021.

doi: $10.21037 / \mathrm{tp}-21-86$

View this article at: https://dx.doi.org/10.21037/tp-21-86 


\section{Introduction}

Acute myeloid leukemia (AML), a malignant clonal disease of hematopoietic stem/progenitor cells, is believed to be initiated from a small sub-population of hematopoietic cells characterized by CD34+/CD38- immunophenotype (1), self-renewal capacity, and thus referred to as leukemia stem cells (LSCs) $(1,2)$. Previous studies demonstrate that LSCs are intimately associated with chemoresistance and radioresistance of AML, which are indicators of malignant behavior, and predictors of poor clinical outcomes $(3,4)$. Obviously, eradication of LSCs is a promising therapeutic strategy and could improve disease prognosis. KG1 $\alpha$ cell line, originally derived from a male patient with AML, is enriched in CD34+/CD38 - cell populations, and is widely used as a (the) cell model for in vitro LSC studies.

Macrophages, a class of immune cells of the mononuclear phagocyte system, are extensively distributed in various body tissues and organs (5). Different macrophage subsets exert distinct effects which are basically dependent on activation states or polarization. Accordingly, polarized M1 macrophages, which are stimulated by lipopolysaccharide (LPS), interferon- $\gamma($ IFN- $\gamma$ ), interleukin-2 (IL-2), tumor necrosis factor- $\alpha$ and granulocyte-macrophage colonystimulating factor (GM-CSF), produce proinflammatory cytokines, such as s IL- $1 \beta$, TNF- $\alpha$, and present proinflammatory phenotype (5). On the other hand, polarized M2 macrophages, frequently stimulated by IL4 or IL13, release/secrete transforming growth factor- $\beta$ (TGF- $\beta$ ) and IL-10 with resultant anti-inflammatory effects (6). Macrophages also play an important role in the onset and progression of solid cancers (7). Similarly, accumulating evidence indicates that close correlation between macrophages and leukemic cells has been observed. Study by Theocharides et al. clearly showed that engraftment of human LSCs in immunocompromised NSG mice was severely impaired by inhibiting macrophage SIRP $\alpha$ signaling (7). In addition, macrophages could be polarized by AML cells, and in turn exhibited proliferationand-progression promoting effects on AML (8). These researches indicate that further studies are needed to better understand the interrelationship between macrophage activation states and LSCs.

Hypoxia, a common pathophysiologic state, plays critical roles in the pathobiology of tissue inflammation and pathology, mediated by diverse mechanisms, such as modulation of macrophage polarization. Several studies have showed that macrophages under in vitro hypoxia exposure, presented with specific gene expression signature, including vascular endothelial growth factor (VEGF), endothelin, endothelial monocyte-activating polypeptideII (EMAPII), angiopoietin 2, and CXCL12 (8). Therefore, upregulation of these proteins promotes survival, recruitment and activation of M1 macrophages, stimulate tissue revascularization and matrix remodeling. Besides the direct effects of hypoxia on LSC, hypoxia-mediated effects on AML can be due both to a direct effect on LSC and to the change in macrophage phenotype.

In the present study, the regulation of macrophage polarization states under in vitro hypoxic exposure, and its effects on malignant behavior of LSCs were explored. Also, the potential mechanisms responsible for malignant behavior of LSC mediated by hypoxia-modulated macrophages were investigated.

We present the following article in accordance with the MDAR reporting checklist (available at https://dx.doi. org/10.21037/tp-21-86).

\section{Methods}

\section{Cell culture and cell sorting}

The human leukemia cell lines KG1 $\alpha$ was cultured in RPMI-1640 medium with addition of $10 \%$ fetal bovine serum (FBS), 1\% penicillin/streptomycin. Eight patients ( 6 boys and 2 girls) with newly diagnosed AML in West China Second University Hospital of Sichuan University (Chengdu, China) from Sept 2019 to Oct 2019 were enrolled in this study. Age at diagnosis ranged from 3-13 years (median age of 8 years). The samples were obtained. Primary AML cells with 95\% of leukemic blasts were isolated by using density gradient separation (FICOLL 400, Sigma-Aldrich) Isolated leukemic cells were cultured in plastic dishes to remove adherent cells at $37^{\circ} \mathrm{C}$ for $24 \mathrm{~h}$. CD34+CD38- cell population was sorted using magnetic microbeads (Miltenyi Biotec, Auburn, CA, USA) following the manufacturer's instructions. All reagents were bought from Life Technologies (Grand Island, NY, USA). Human monocytic THP-1 cells were cultured in RPMI1640 supplemented with $10 \% \mathrm{FBS}, 2.5 \mathrm{~g} / \mathrm{L}$ D-glucose and $50 \mathrm{pM}$ $\beta$-mercaptoethanol.

The study was conducted in accordance with the Declaration of Helsinki (as revised in 2013). The study was approved by the Institutional Ethics Committee of the West China Second University Hospital of Sichuan University. Written informed consent was obtained from individual or 
guardian participants.

\section{Cell cycle analysis}

Cells were collected by centrifugation at $1,000 \mathrm{rpm}$ for 5 min. Pelleted cells were washed with ice-cold PBS twice, centrifuged at 1,000 rpm for $5 \mathrm{~min}$. Then cells were fixed with $70 \%$ ice-cold ethanol for $16 \mathrm{~h}$. Fixed cells were washed with ice-cold PBS and suspended with staining buffer (BD pharmingen, San Diego, CA, USA) and incubated for $10 \mathrm{~min}$ at room temperature. Then the cells were analyzed by flow cytometry (BD FACS Canto II, BD Biosciences, San Jose, CA, USA).

\section{$R T-q P C R$}

For quantitative analysis of gene expression, total RNA was extracted using TRIzol reagent (Life Technologies, Grand Island, NY, USA) and reverse transcribed into cDNA. The cDNA was employed as template for RT-qPCR with SsoFast Eva-Green Supermix (Bio-Rad, Hercules, CA, USA). Relative expression was normalized to $\beta$-actin mRNA and was served as an internal control. The following PCR conditions were used on the LightCycler: $95^{\circ} \mathrm{C}$ for $5 \mathrm{~s}$, $58^{\circ} \mathrm{C}$ for $5 \mathrm{~s}$, followed by 40 cycles of $95^{\circ} \mathrm{C}$ for $15 \mathrm{~s}$ and $60{ }^{\circ} \mathrm{C}$ for $1 \mathrm{~min}$ in a $10-\mu \mathrm{L}$ reaction volume. The primer sequences for RT-qPCR were listed as followed: IL- $1 \beta$ forward 5'-ATGATGGCTTATTACAGTGGCAA-3' and reverse 5'-GTCGGAGATTCGTAGCTGGA-3'; TNF- $\alpha$ forward 5'-CСТСТСТСТAATCAGCССТCTG-3' and reverse 5'-GAGGACCTGGGAGTAGATGAG-3'; VEGF forward 5'-AGGGCAGAATCATCACGAAGT-3' and reverse 5'-AGGGTCTCGATTGGATGGCA-3'; HLADR forward 5'-AGTCCCTGTGCTAGGATTTTTCA-3' and reverse 5'-ACATAAACTCGCCTGATTGGTC-3'; CCL17 forward 5'-CTGCAAAGCCTTGAGAGGTC-3' and reverse 5'- TCCCTCACTGTGGCTCTTCT-3'; $\beta$-actin forward 5'-CATGTACGTTGCTATCCAGGC-3' and reverse 5'-CTCCTTAATGTCACGCACGAT-3.

\section{Macrophage polarization under hypoxic or normoxic condition}

THP-1 cells were firstly differentiated into macrophages by co-culturing with $150 \mathrm{nM}$ phorbol 12-myristate 13-acetate (PMA, Sigma-Aldrich, St. Louis, MO, USA) for $24 \mathrm{~h}$. Differentiated macrophages were incubated with $10 \mathrm{pg} / \mathrm{mL}$ of LPS (Sigma-Aldrich, St. Louis, MO, USA) and $20 \mathrm{ng} / \mathrm{mL}$ of IFN- $\gamma$ (R\&D systems, Minnesota, USA) for M1 polarization. M2-polarized macrophages were incubated with $20 \mathrm{ng} / \mathrm{mL}$ IL-4 (R\&D systems, Minnesota, USA). To access the effects of hypoxia on polarization of macrophages, unpolarized macrophages were cultured under hypoxic condition $\left(1 \% \mathrm{O}_{2}\right)$ in a gas generator system (Model MCO $18 \mathrm{M}$; Sanyo Biomedical Electrical Co, Tokyo, Japan) with $10 \mathrm{pg} / \mathrm{mL}$ of LPS, $20 \mathrm{ng} / \mathrm{mL}$ of IFN- $\gamma$ or $20 \mathrm{ng} / \mathrm{mL}$ of IFN- $\gamma$.

\section{Cell viability assay}

$10 \mu \mathrm{L}$ tetrazolium salt (CCK-8, Sigma-Aldrich, St. Louis, MO, USA) was added into cells and incubated for $30 \mathrm{~min}$. Optical density was measured at a wavelength of $450 \mathrm{~nm}$ (OD450).

\section{Soft agar assay}

For this assay, $1 \times 10^{4}$ cells were plated in $0.3 \%$ low-melt agarose on top of a $0.6 \%$ agarose melted in conditioned medium. Cells in agarose were allowed to grow for 3 weeks in $\mathrm{CO} 2$ incubator at $37^{\circ} \mathrm{C}$. Pictures were taken and the number of colonies was counted using a X71 (U-RFL-T) fluorescence microscope (Olympus, Melville, NY, USA).

\section{Enzyme-linked immunosorbent assay (ELISA)}

The levels of cytokines, including IL-1 $\beta$, TNF- $\alpha$, VEGF, and CCL17 in supernatant were measured with ELISA kits (Nanjing Jingcheng Bioengineering Institute, Nanjing, China) according to the manufacturer's instructions.

\section{RNA knockdown}

siRNA targeting survivin mRNA was followed as: 5'-CACCGCAUCUCUCUACAUUCATT-3' (sense) and 5'-UGAAUGUAGAGAGAUGCGGUGTT-3' (antisense); $2 \mu \mathrm{g}$ survivin siRNA or control siRNA were transiently transfected into cells for $48 \mathrm{~h}$ using the Lipofectamine PlusTM reagent (Gibco BRL, USA) following the manufacturer's instructions and used for further study.

\section{Apoptosis assay}

Apoptosis was evaluated using Annexin V-FITC/PI apoptosis detection kit (BD Biosciences, Franklin Lakes, NJ, USA) by flow cytometry analysis. Briefly, cells were 
stained with $3 \mu \mathrm{L}$ FITC-labeled annexin and $5 \mu \mathrm{L}$ of PI for 30-minute staining. Then cells were directly analyzed using 3 laser Navios flow cytometers (Beckman Coulter, Brea, CA, USA).

\section{Western blot}

Western blot was carried out as described previously (9). Briefly, cells were lysed using SoniConvert ${ }^{\circledR}$ homogenizer (DocSense, Chengdu, China). Then the total protein content was measured using Bradford's reagent. $20 \mu \mathrm{g}$ of total protein was loaded for SDS-PAGE and immunoblotting was carried out using specific antibodies. The primary antibodies used are listed as follows: AntiVEGFA antibody (Cat. No.: ab52917), anti-Survivin antibody (Cat. No.: ab76424), anti-cleaved PARP1 antibody (Cat. No.: 32064), anti-active caspase-3 antibody (Cat. No.: ab32042). All primary antibodies were purchased from Abcam (Cambridge, England) and diluted in 1: 2000. Secondary antibody used is Goat anti-rabbit secondary antibody and diluted in 1:10,000. Imaging was carried out using enhanced chemiluminescence (ECL, Life Technologies, Grand Island, NY, USA) kit.

\section{Statistical analysis}

Statistical analysis was carried out using SPSS 14.0 (SPSS, Inc., Chicago, IL, USA). Data was presented as the mean \pm SEM. One-way analysis of variance (ANOVA) or twoway ANOVA was performed to compare multiple groups with one or two variables followed by Tukey's post-hoc test, respectively. $\mathrm{P}<0.05$ was considered as statistically significant. All experiments were performed at least three times.

\section{Results}

\section{Sorting of leukemic cells with stem-cell immunophenotype from $K G-1 \alpha$}

The KG-1 $\alpha$ cell line, derived from a male AML patient, is enriched in cell subset endowed with LSC characteristics, a feature shared by many other stabilized leukemia cell lines and is widely used for LSC sorting which presented CD34+CD38- (10). In this study, well-cultured KG-1 $\alpha$ cells were bought from ATCC (cat. No.: ATCC-CCL-246.1, Manassas, VA, USA) and kept in liquid nitrogen in our laboratory. Well-cultured cells were employed for fluorescence-activated cell sorting (FACS) analysis, in order to enrich CD34+CD38- sub-population, which presents characteristics of stem cells. As shown in Figure 1A, in original, the proportion of CD34+CD38- subset accounted for $17.6 \% \pm 1.2 \%$ of the original KG- $1 \alpha$ cell population which increased to $88.2 \% \pm 3.7 \%$ after sorting using magnetic beads), indicating successful enrichment of LSCs. Subsequent cell cycle analysis showed that there were no significant differences in terms of cell proportions distributed in distinct cell cycle phases between enriched LSCs and parental KG-1 $\alpha$ cells (Figure 1B).

\section{Effects of hypoxia on the polarization tendency of M1-M2 balance}

Human immatured macrophages were employed for generation of Macrophages (M $\varphi)$, (M1 or M2 activation states were established by stimulation with LPS/IFN- $\gamma$ or IL-4, respectively. Thereafter, levels of cytokines/ chemokines associated with M1 or M2 polarization were quantitated by ELIASA normalized against those in unstimulated $M \varphi$ cells. As shown in Figure $2 A$, levels of M1-specific cytokines including IL- $1 \beta$, TNF- $\alpha$, and HLA-DR in LPS/INF- $\gamma$-stimulated cells were significantly higher than that in $\mathrm{M} \varphi$ group $(\mathrm{P}<0.05$ vs. $\mathrm{M} \varphi$ group). As expected, levels of M2-specific cytokines/ chemokines including VEGF and CCL17 in IL-4stimulated cells were significantly elevated as compared to $\mathrm{M} \varphi$ cells $(\mathrm{P}<0.05$ vs. $\mathrm{M} \varphi$ group).

Notably, relative upregulation of VEGF was observed in LPS/INF- $\gamma$-stimulated cells, potentially due to the proportion of unspecific polarized macrophages. States of polarization were further confirmed by surface expression of macrophage differentiation markers using flowcytometry. CD86, the marker of M1 polarization, was highly expressed in LPS/IFN- $\gamma$-stimulated cells, indicating successful induction of M1 phenotype (Figure 2B). Similarly, CD206, the marker of M2 polarization, was significantly upregulated in IL4-stimulated cells, signifying M2 phenotype.

In order to study the impact of hypoxia-modulated polarized macrophages on the induction of inflammatory microenvironment, LPS/IFN- $\gamma$ and IL-4 stimulated macrophages were specifically cultured under normoxia $\left(20 \% \mathrm{O}_{2}\right)$ and hypoxia $\left(1 \% \mathrm{O}_{2}\right)$ conditions. Then, mRNA expressions of cytokines/chemokines were determined. As shown in Figure 2C, hypoxic exposure significantly reduced the mRNA levels of proinflammatory IL-1 $\beta$ and TNF- $\alpha$ in LPS/IFN- $\gamma$ stimulated macrophages $(11,12)$. 

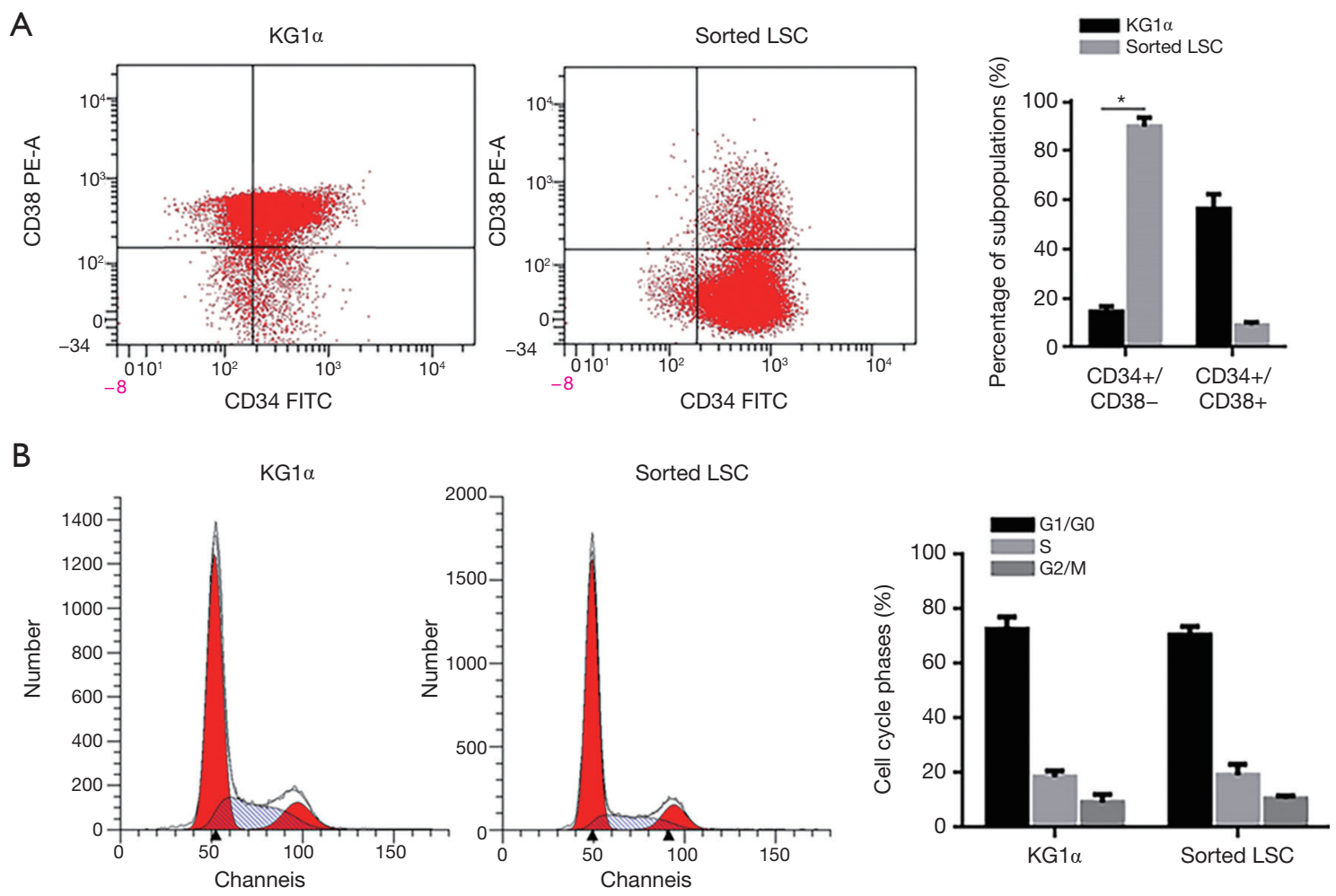

Figure 1 Leukemia stem-like cells were sorted from KG1 $\alpha$ cells by flow cytometry. (A) Sorted cells were identified using flow cytometry. Before sorting, the CD34+CD38- cells were $16.5 \% \pm 0.9 \%$; after sorting, the CD34+CD38- cells were $91.3 \% \pm 4.7 \%$. (B) Cell cycle phases were then analyzed to determine whether sorted cells is different with parental cells in proliferation. ${ }^{*} \mathrm{P}<0.05$.

Notably, hypoxic exposure remarkably upregulated the mRNA levels of VEGF in both LPS/IFN- $\gamma$ and IL-4 stimulated macrophages under hypoxia as compared to that under normoxia. In addition, Cytokine/chemokine levels under different culture conditions were assayed by ELISA. Consistent with mRNA expression patterns, levels of IL-1 $\beta$ and TNF- $\alpha$ were decreased in M1-polarized macrophages under hypoxia as against cells under normoxia, while VEGF level was increased in M2-polarized hypoxiaexposed macrophages compared to their counterparts under normoxia (Figure 2D). Flowcytometric studies showed that hypoxia significantly upregulated CD206 expression and downregulated CD86 expression when compared to that in counterpart cells under normoxia. Expectedly, hypoxic exposure significantly reduced the protein levels of proinflammatory IL- $1 \beta$ and TNF- $\alpha$ in supernatant of LPS/IFN- $\gamma$ stimulated macrophages (Figure $2 E$ ). Western blot clearly indicated that VEGF-A protein expression was upregulated in different cell populations under hypoxic exposure (Figure $2 F$ ), suggesting VEGF might mediate the induction of inflammatory microenvironment).

\section{Hypoxia-mediated microenvironment enhances LSC proliferation, colony-forming capacity and chemoresistance}

Next, we tried to explore possible effects of hypoxic microenvironment primed by distinct polarized M1 macrophage on LSCs. LSCs were exposed to LPS/IFN- $\gamma$ / normoxia conditioned medium (N-CM) or LPS/IFN- $\gamma /$ hypoxia conditioned medium (H-CM) respectively. Increased LSCs cell viabilities determined by performing CCK-8 at 24-hour and 48-hour were clearly demonstrated when coincubated with $\mathrm{H}-\mathrm{CM}$ as compared to LSCs (that) with $\mathrm{N}-\mathrm{CM}$ (Figure $3 A$ ). In addition, LSCs under H-CM exhibited remarkably enhanced colony-forming capacity (Figure 3B), and increased resistance treated with commonly used chemotherapeutic agents respectively (cytarabine, Dexamethasone, or L-Asparaginase) (Figure 3C). Putting together, these findings suggested that hypoxic microenvironment induced by specific macrophage 
A

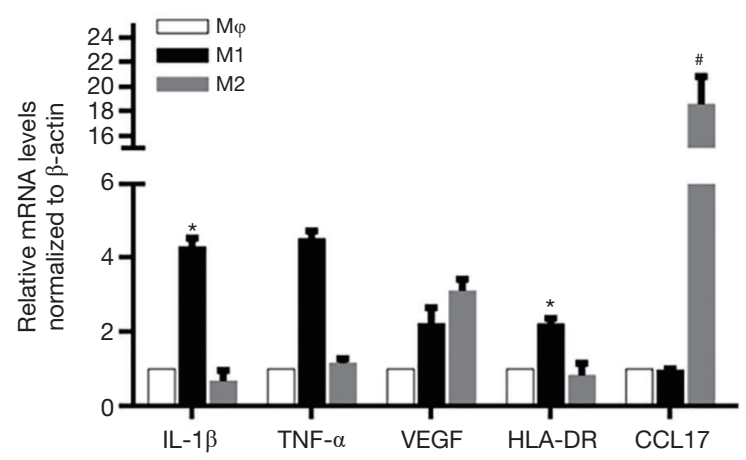

B

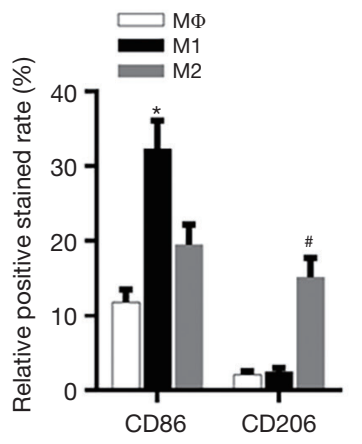

C

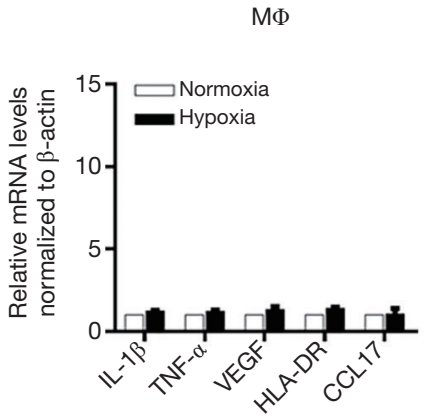

D

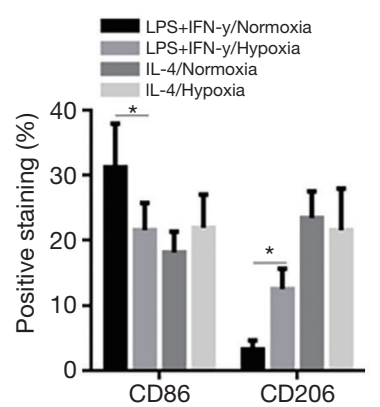

$\mathrm{E}$

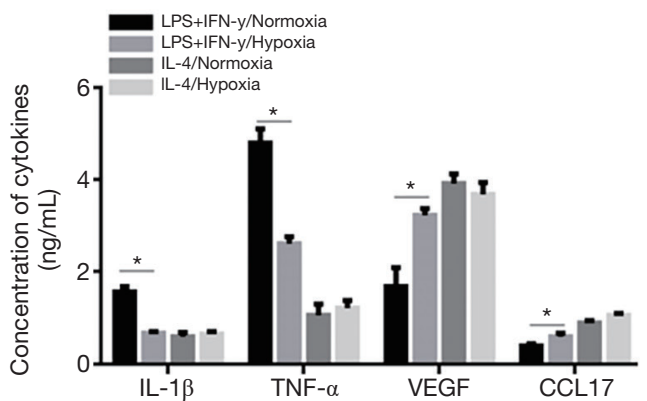

M2

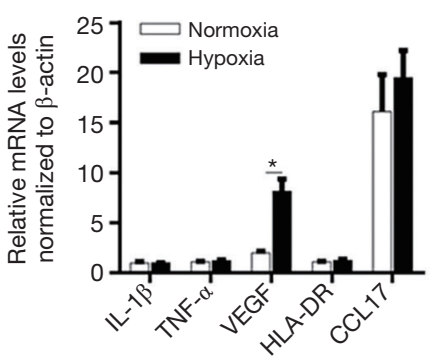

$\mathrm{F}$

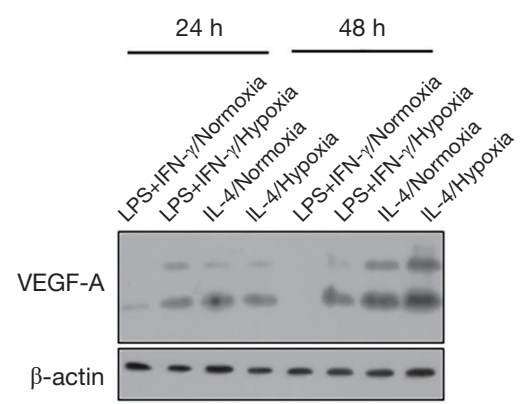

Figure 2 The effects of hypoxia exposure on macrophage polarization. (A) After specific stimulation, mRNA levels of cytokines, including IL-1 $\beta$, TNF $\alpha$, VEGF, HLA-DR and CCL17 were quantitatively analyzed. ${ }^{*} \mathrm{P}<0.05$, vs. M $\varphi$ group. ${ }^{*} \mathrm{P}<0.01$, vs. M $\varphi$ group; (B) flow cytometric analysis was performed to determine the surface markers of macrophages after specific stimulation. ${ }^{*} \mathrm{P}<0.05$, vs. $\mathrm{M} \varphi$ group. ${ }^{\#} \mathrm{P}<0.01$, vs. M $\varphi$ group. (C) The effects of hypoxia or normoxia on cytokine expression of M1- or M2-polarized macrophages. ${ }^{*} \mathrm{P}<0.05$, vs. normoxia group. (D) The released cytokines in supernatant were detected after hypoxia- or normoxia-exposed macrophages. ${ }^{*} \mathrm{P}<0.05, v s$. LPS+IFN- $\gamma /$ normoxia group. (E) The surface marker genes of macrophages were analyzed by flow cytometry after hypoxia or normoxia exposure. ${ }^{*} \mathrm{P}<0.05$, vs. LPS+IFN- $\gamma /$ normoxia group. (F) The expression of VEGF-A in hypoxia- or normoxia-exposed macrophages was analyzed by western blot. 
A

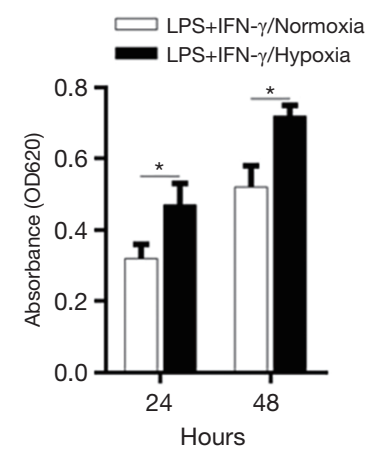

C
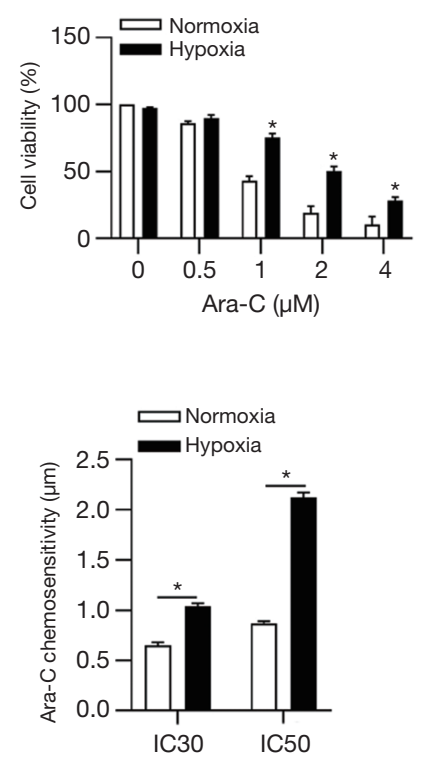
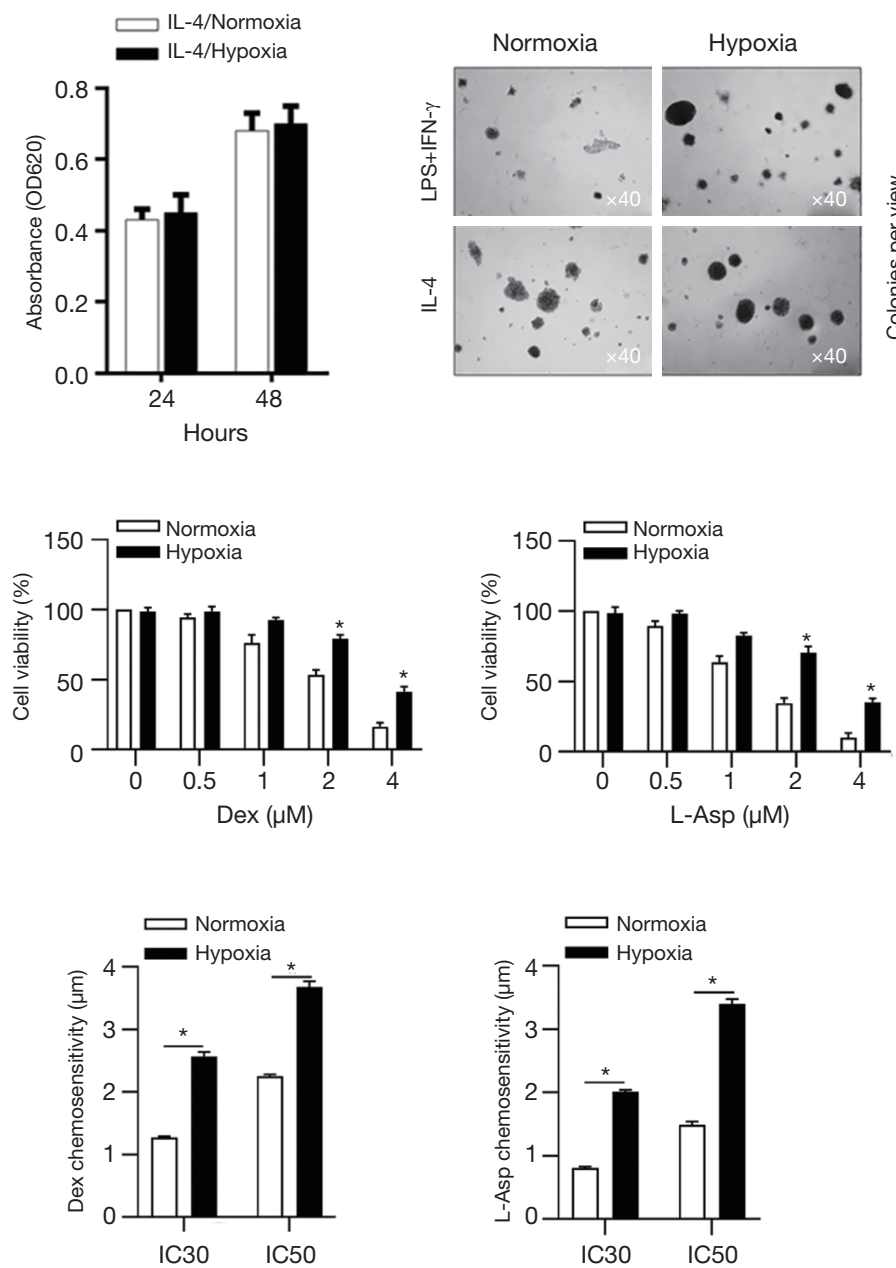

B

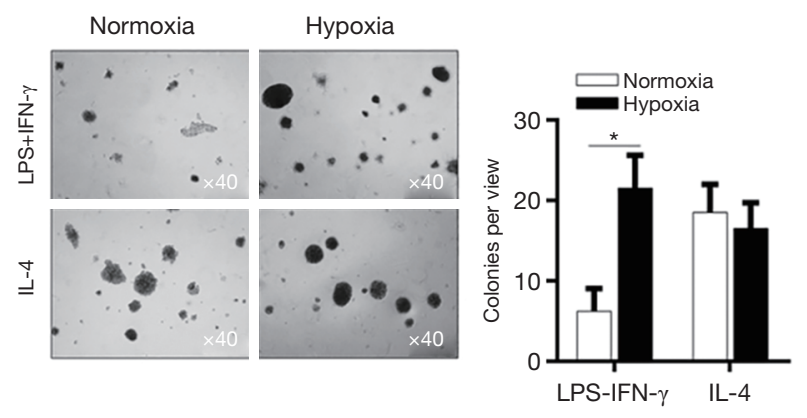

Figure 3 The effect of hypoxia-modified microenvironment on malignant behaviors and chemoresistance of LSCs. (A-C) The effect of hypoxia or normoxia modified microenvironment on proliferation, colony formation of LSCs was identified. ${ }^{*} \mathrm{P}<0.05$, vs. normoxia group.

polarization contributed to promotion of proliferation and enhanced chemoresistance of LSCs.

\section{VEGF-mediated survivin upregulation potentially induces chemoresistance}

Previous study indicated that VEGF was closely implicated in chemoresistance of endothelial cells by transcriptionally inducing survivin expression (13). Our study showed that addition of VEGF upregulated survivin protein expression in LSCs incubated in the setting of M1 polarization under normoxia, which could be blocked by Pazopanib ( $30 \mathrm{nM})$, a VEGF receptor inhibitor (Figure $4 A$ ). Notably, survivin was obviously upregulated in LSCs under hypoxic condition
(Figure 4A). LSCs co-incubated with distinct conditioned mediums were treated with $2 \mu \mathrm{M}$ cytarabine. As illustrated in Figure 4B, VEGF decreased cellular apoptosis which could be reversed by Pazopanib, indicating that induction of chemoresistance might be mediated by VEGF. When LSCs under hypoxia were initially treated with survivinspecific siRNA to knockdown its expression (Figure 4C), and subsequently treated with cytarabine $(2 \mu \mathrm{M})$ for 24 hours, apoptotic rate was again determined. It revealed that survivin knockdown (down regulation) significantly increased apoptosis of LSCs under hypoxia, but failed to induce apoptosis of LSCs under normoxia (Figure 4D), which might be related to low level of survivin expression in the latter setting (Figure 4D). 
A

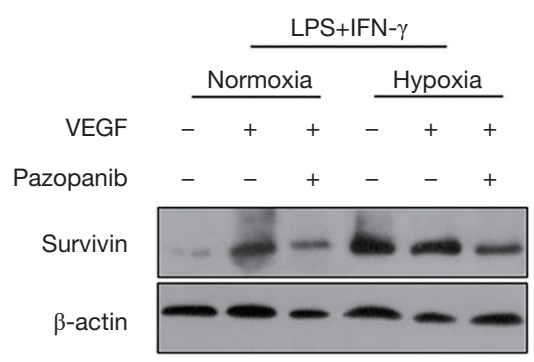

B

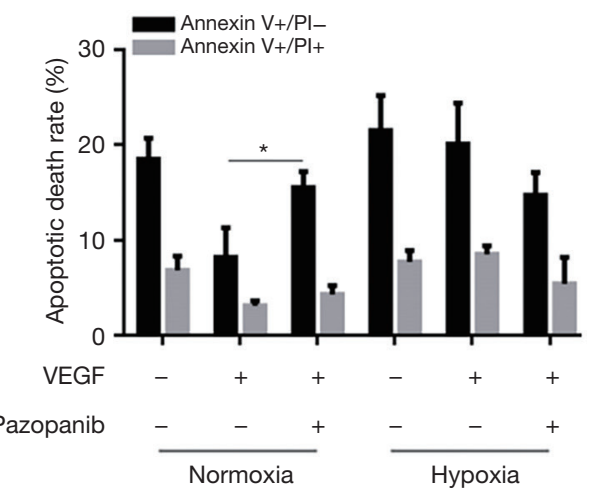

C

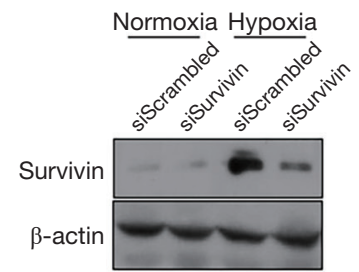

E
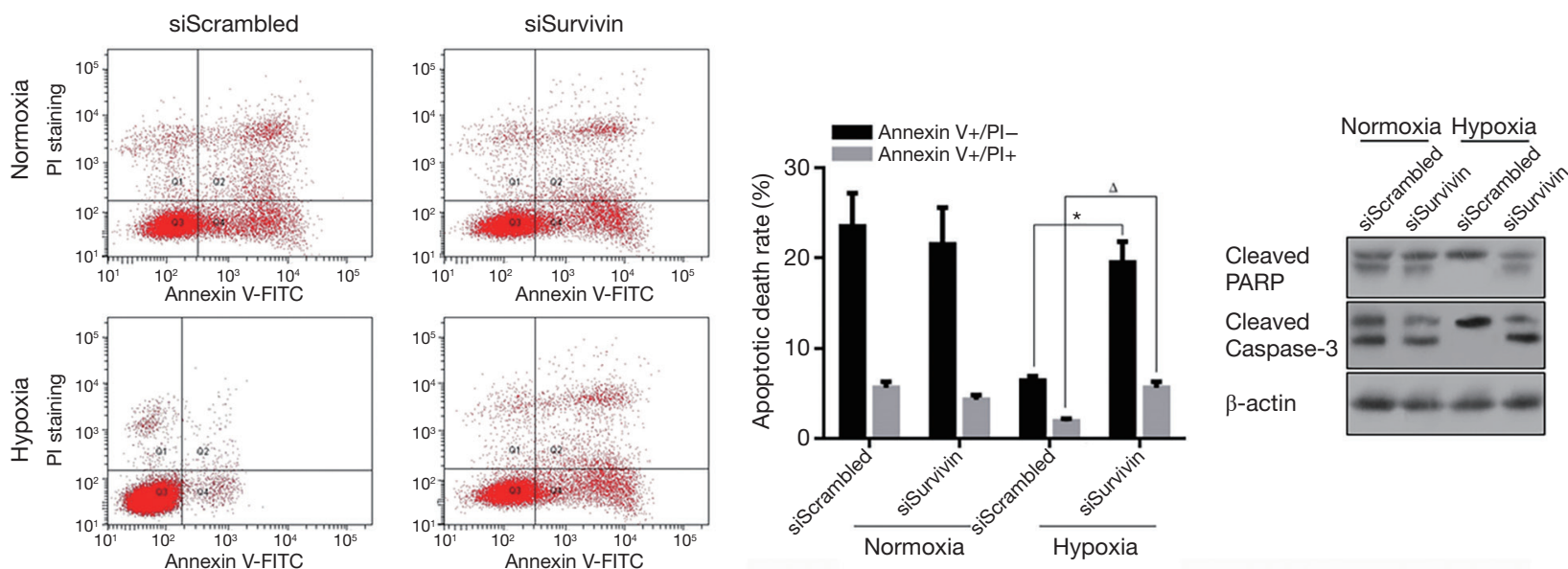

Figure 4 Hypoxia-induced VEGF upregulated Survivin and potentially contributes to chemoresistance in this manner. The Survivin protein levels $(\mathrm{A})$ and relative apoptotic cell death rate $(\mathrm{B} \& \mathrm{C})$ was measured in macrophages cultured in hypoxia-modified microenvironment. Survivin knockdown efficacy was measured by semiquantitative western blot after transfection of siRNA target to Survivin mRNA. Annexin V-FITC/PI double staining followed by flow cytometry (D), ${ }^{*} \mathrm{P}<0.05$ vs. siScrambled group; $\Delta \mathrm{P}<0.05$, vs. siScrambled group) and semiquantitative western blot for detecting cleaved PARP and cleaved caspase-3 (E) were carried out to detect apoptotic cell death rate after Survivin knockdown.

Western blots clearly showed that expressions of apoptosis-specific proteins cleaved PARP and cleaved caspase-3 in survivin knockdown LSCs under hypoxia were markedly downregulated (Figure 4E), which were consistent with apoptotic phenotype observed in Figure 4D.

\section{H-CM transcriptionally upregulated HIF-1 $\alpha$ potentially via VEGF}

Previous study demonstrated that HIF- $1 \alpha$ transcriptionally activated expression of VEGF, a critical factor involved in angiogenesis, and VEGF in turn modulated HIF- $1 \alpha$ expression at transcriptional level, thus creating a feedback loop (between them) (14). Accordingly, we set out to explore whether VEGF might mediate upregulation of HIF-1 $\alpha$ in LSCs under the setting of H-CM. Our study firstly showed that VEGF transcription in LSCs was significantly induced after 48-hour exposure to H-CM and was inhibited by pazopanib (Figure $5 A$ ), supporting a potential feedback loop between HIF-1 $\alpha$ and VEGF. Secondly, we found that expressions of HIF- $1 \alpha$ mRNA and protein in LSCs were upregulated when treated with $\mathrm{H}-\mathrm{CM}$, VEGF, hypoxia or $\mathrm{CoCl} 2$ (Figure $5 B$ and $5 C$ ). Luciferase reporter assay further showed that upregulation of HIF-1 $\alpha$ protein was abolished 
A

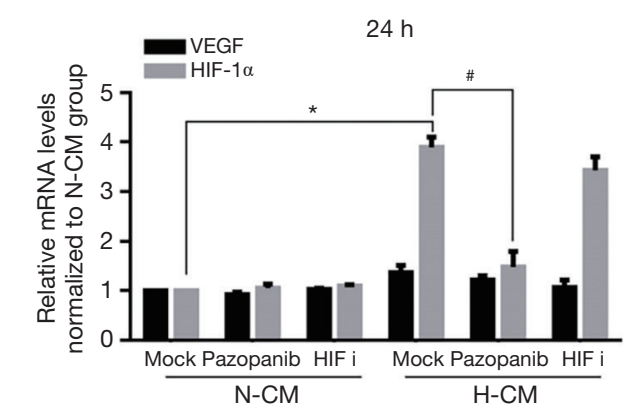

C

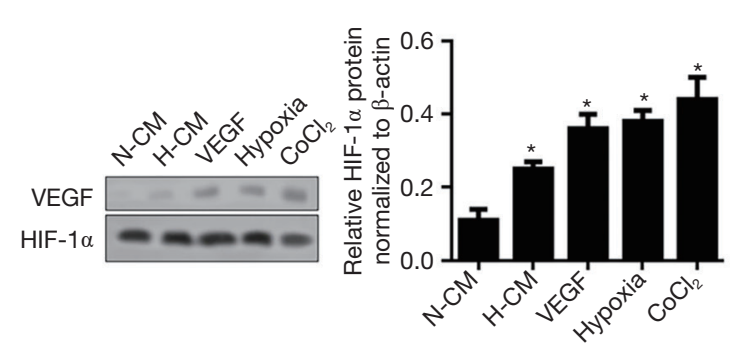

B

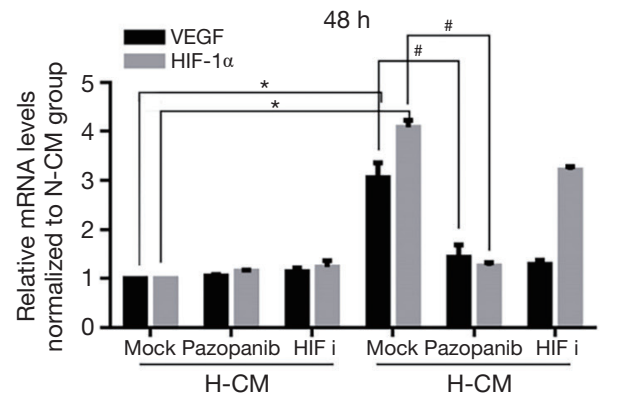

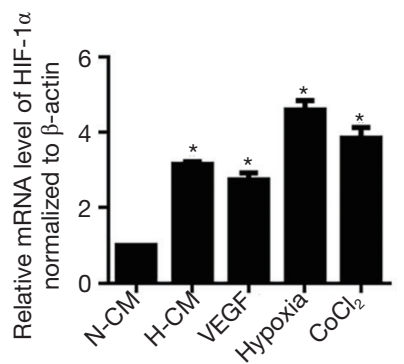

D

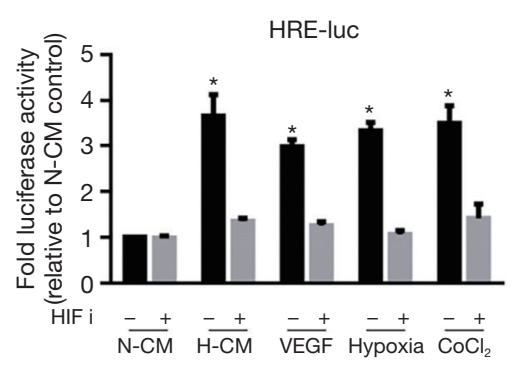

Figure $5 \mathrm{H}-\mathrm{CM}$ transcriptionally activated HIF-1 $\alpha$ and induced its transcriptional activity. (A) After 24 or $48 \mathrm{~h}$ after N-CM or H-CM exposure, RT-qPCR was performed to measure mRNA levels of VEGF and HIF- $1 \alpha .{ }^{*} \mathrm{P}<0.05$ vs. $\mathrm{N}-\mathrm{CM}$ group. ${ }^{*} \mathrm{P}<0.05$ vs. Mock group. (B) RT-qPCR was performed to detect HIF- $1 \alpha$ mRNA level after H-CM exposure in LSCs. ${ }^{*} \mathrm{P}<0.05$ vs. N-CM group. (C) Western blot was performed to detect HIF-1 $\alpha$ protein levels. ${ }^{*} \mathrm{P}<0.05$ vs. $\mathrm{N}$-CM group. (D) Luciferase reporter gene assay was performed to detect whether $\mathrm{H}-\mathrm{CM}$ exposure induced transcriptional activity of HIF- $1 \alpha$.

by HIF I (Figure 5D). In addition, transcriptional induction of HIF- $1 \alpha$ in LSCs was significantly suppressed by VERF$2 \mathrm{R}$ inhibitor pazopanib, but not by HIF-I determined at 24 hours and 48 hours after H-CM exposure (Figure 5A), strongly indicating that upregulation of HIF- $1 \alpha$ expression was mediated by VEGF. In order to test whether VEGF could mediate induction of HIF- $1 \alpha$ expression in primary LSCs, leukemic cells and sorted leukemic cells with CD34+/ CD38- immune-phenotype isolated from untreated AML patients.

It turned out that mRNA expression levels of both HIF- $1 \alpha$ and survivin were significantly lower in sorted LSCs than that in unsorted primary AML leukemic cells (Figure 6A). HIF-1 $\alpha$ and survivin mRNA expressions were remarkably increased in sorted primary LSCs as compared to unsorted primary AML cells after VEGF treatment (Figure 6B), suggesting VEGF-mediated HIF-1 $\alpha$ induction in sorted KG1 $\alpha$ representing in vitro LSC cell model also happened ex vivo. Again, primary LSCs presented with increased resistance to chemotherapeutic agents (cytarabine, dexamethasone, L-Asparaginase) under $\mathrm{H}-\mathrm{CM}$ as compared to N-CM (Figure $6 C$ and Figure S1).

\section{H-CM exerts protective effects on LSCs via VEGF-mediated HIF-1 $\alpha$ induction}

To test the hypothesis that hypoxic microenvironment primed by H-CM might provide a protection for LSCs via VEGF/HIF-1 $\alpha$ signaling, cells cultured in H-CM were treated with pazopanib or HIFi. As shown in Figure $7 \mathrm{~A}$ and B, cell cycle arrest at G1/G0 and growth inhibition were observed in cells under $\mathrm{H}-\mathrm{CM}$ with pazopanib or HIFi treatment. In addition, these cells exhibited increased chemoresistance (Figure 7C) and reduced cell apoptosis (Figure $7 D$ ). Putting together, our findings validated the observation that HIF- $1 \alpha$ is (was) required for survival maintenance of chronic myeloid leukemia stem cells (15).

\section{Discussion}

LSCs are intimately implicated in leukemogenesis, including AML. High quantity of LSCs are generally correlated with poor outcome (16). Researches on relevant signaling pathways and regulatory mechanisms of LSCs help to further understand leukemia initiation and 
A
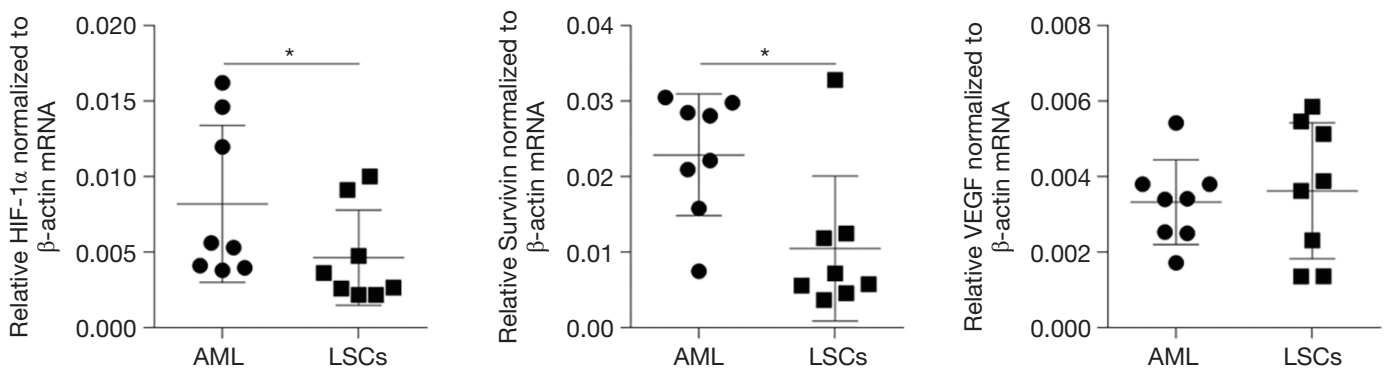

B
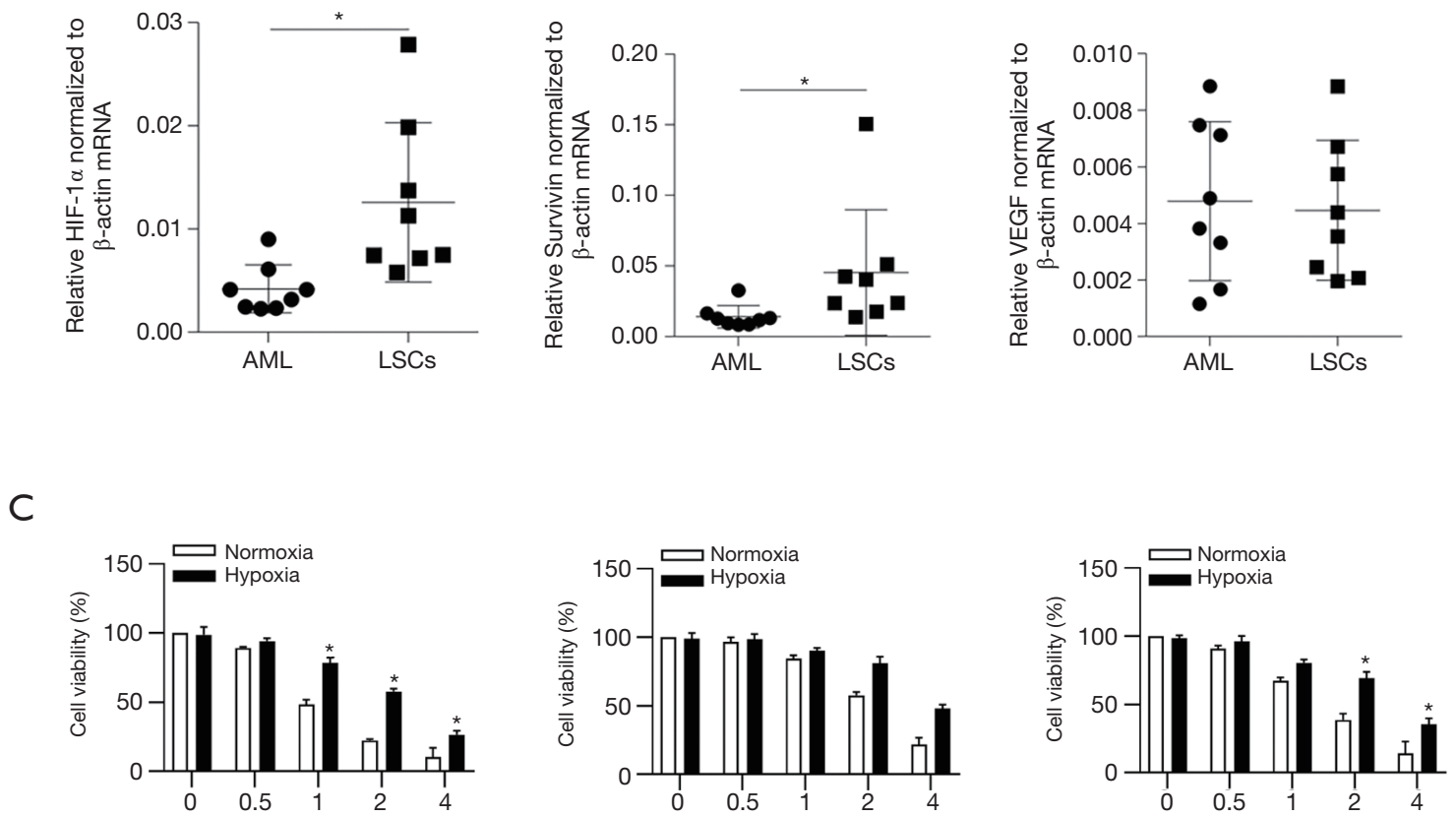

Figure 6 The effects of VEGF on expressing levels of HIF-1 $\alpha$, Survivin and VEGF in primary LSCs. (A) The expressing levels of HIF-1 $\alpha$, Survivin and VEGF in LSCs compared to AML were measured. ${ }^{*} \mathrm{P}<0.05$, vs. AML group. (B) After VEGF treatment, the expressing levels of HIF-1 $\alpha$, Survivin and VEGF in LSCs compared to AML were measured. ${ }^{*} \mathrm{P}<0.05$, vs. Mock group. (C) Chemosensitivity was measured by performing CCK-8 assay. ${ }^{*} \mathrm{P}<0.05$. vs. normoxia group.

progression, and to develop novel LSC-targeting therapies. The present study demonstrated that patterns of cytokine secretion by macrophages under hypoxic exposure were stimulation-dependent. Proinflammatory cytokines, such as IL- $1 \beta$ and TNF- $\alpha$, were produced significantly by macrophages when stimulated by LPS and INF- $\gamma$, while VEGF production was predominantly triggered when stimulated by IL-4. This indicates that hypoxia sets up an inflammatory microenvironment by regulating the secretion of proinflammatory cytokines (Figure 1). In addition, hypoxia promoted macrophage polarization shifting toward
M2 state (Figure 2).

Recent studies indicate that biology of LSCs is closely associated with microenvironment, in terms of selfrenewal promotion, adhesion and homing, and abnormal activation of pro-survival signal cascades (17). Given the fact that LSCs are normally localized in hypoxic conditions, strategies targeting the microenvironment are of potential therapeutic importance (17). Therefore, we focus the effects that hypoxia might exert on the biology of LSCs.

Previous studies show that hypoxia sustains survival of AML cells by activating the PI3K/Akt/mTOR pathway and 
A
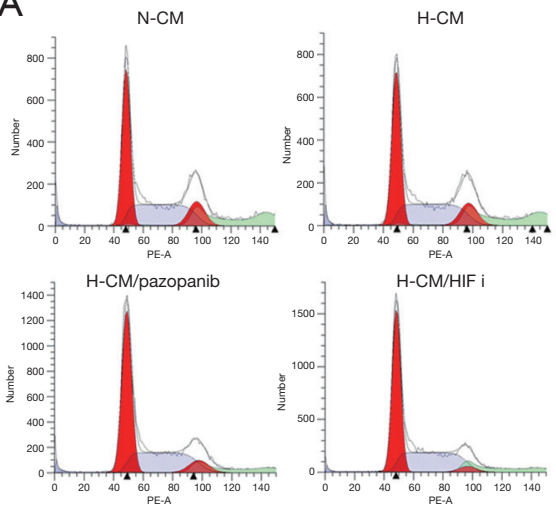

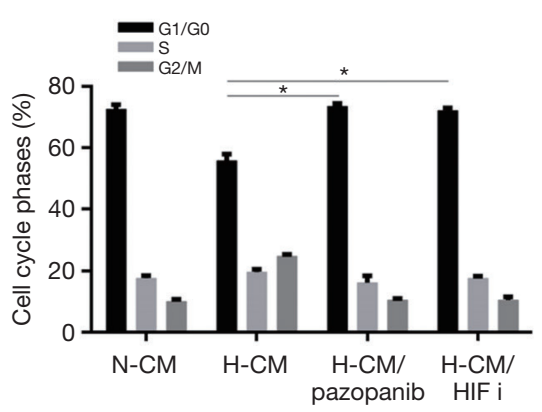

B

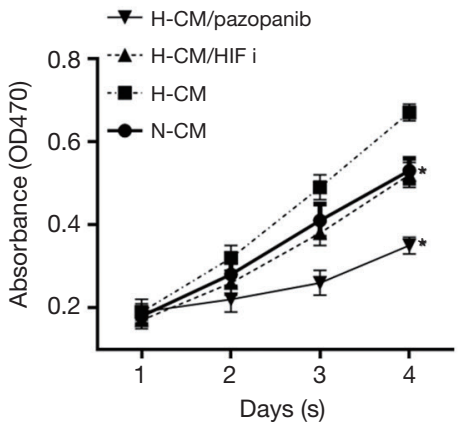

C
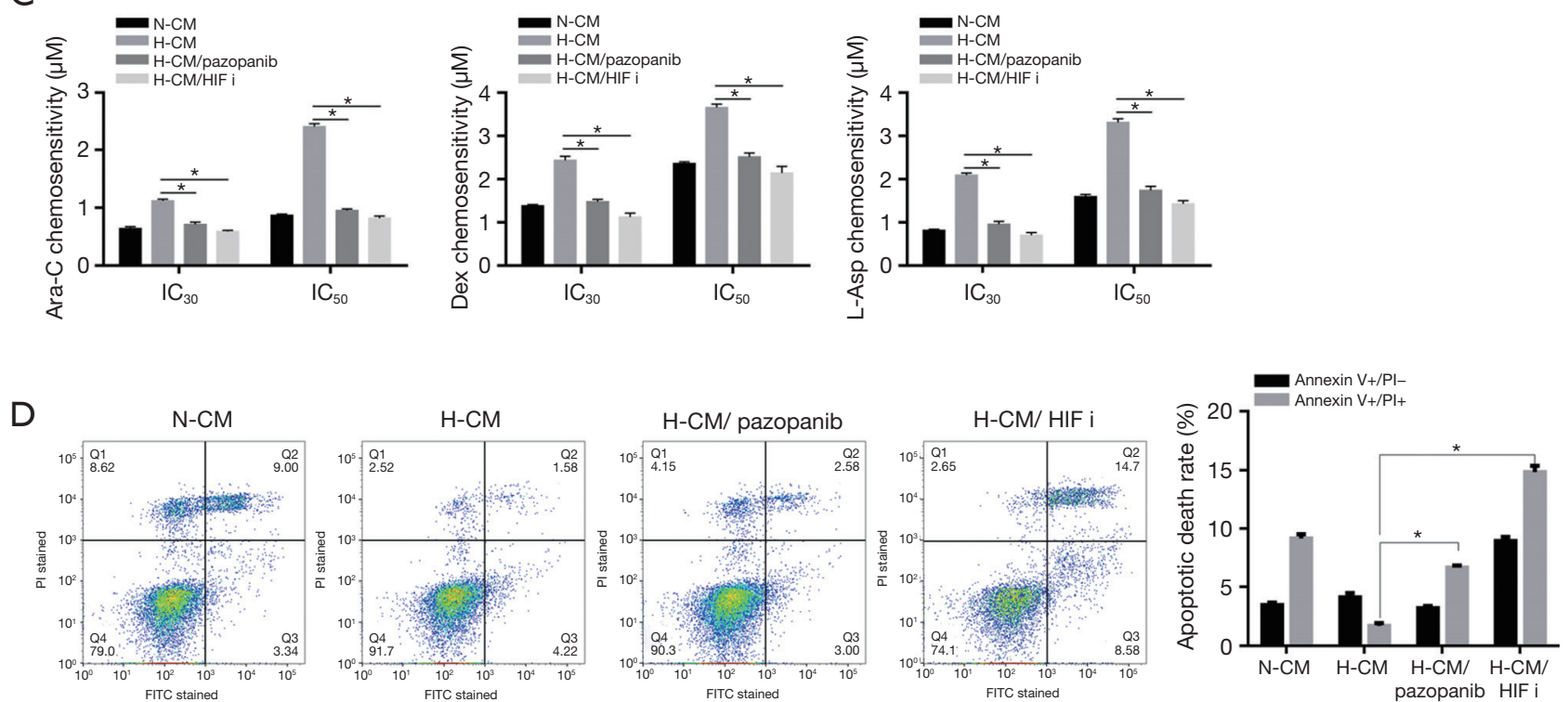

Figure 7 H-CM induced HIF-1 $\alpha$ by VEGF promoted proliferation and exerted protective effects against chemotherapy. (A) Cell cycle phases were measured by performing PI staining followed by flow cytometry assay. ${ }^{*} \mathrm{P}<0.05 v$ s. H-CM group. (B) CCK-8 assay was performed to detect cell viability. ${ }^{*} \mathrm{P}<0.05$ vs. H-CM group. (C) Chemosensitivity was measured by performing CCK-8 assay. ${ }^{*} \mathrm{P}<0.05$ vs. H-CM group. (D) Apoptosis was measured by Annexin V-FITC/PI double staining followed by flow cytometry assay. ${ }^{*} \mathrm{P}<0.05$ vs. $\mathrm{H}-\mathrm{CM}$ group.

Pim-1 expression $(15,16)$, resulting in better adaption to hypoxia $(17,18)$. Nevertheless, the underlying mechanisms that hypoxia influences microenvironment remain to be clarified. We found that hypoxia primed macrophages toward M2 polarization, induced a proinflammatory microenvironment, remarkably promoted malignant behavior of LSCs $(17,18)$, and enhanced chemoresistance (Figure 3).

By considering the decrease of pro-inflammatory cytokine secretion, IL-1 $\beta$ or TNF- $\alpha$ was supplemented in conditioned medium for the aim of figuring out whether these cytokines are responsible for tumor promoting effects. Our finding that IL-1 $\beta$ or TNF- $\alpha$ failed to significantly reverse tumor-promoting effects, indicates that hypoxiamediated tumor-promoting effects could not been explained by change of single factor

VEGF, secreted primarily by macrophages, plays various important functions including angiogenesis, promotion of malignancies $(19,20)$. Studies reveal that VEGF promotes and recruits M2 polarized macrophages (20). 
We hypothesize that promotion of malignancy might be achieved by VEGF-mediated upregulation of expression of anti-apoptotic proteins, including bcl-2 (21), X-linked inhibitor of apoptosis (XIAP) $(22,23)$, and survivin (24). In fact, we showed that VEGF significantly upregulated the expression of survivin, but had no effects on the expressions of bcl-2 and XIAP). Further, we demonstrated that VEGF-induced survivin upregulation contributed partly to chemoresistance and anti-apoptotic features of LSCs treated with CM.

In summary, our findings suggest that inflammatory microenvironment induced by hypoxia-mediated specific paradigm of M2 macrophage polarization modulates malignant behavior of LSCs. Because of the unpredictable expression patterns of cytokines, which essentially regulates inflammatory microenvironment, the malignant behaviors of LSCs affected by inflammatory microenvironment are still largely unknown. Therefore, further studies are needed to elucidate the signaling transduction modifying LSC biology which could be manipulated in developing novel therapies.

\section{Acknowledgments}

We thank Professor Dongsheng Liao (Sichuan University) and Joseph Torres (University of Texas Medical Branch) for language editing.

Funding: The present study was supported by grants from the Application Foundation Program of Science and Technology Department of Sichuan Province (grant no. 19ZDYF1202, 2020YFS0253), the National Science Foundation for Young Scientists of China (grant no. 81600122), The General Program (Key Program, Major Research Plan) of National Natural Science Foundation of China (grant no. 82074298).

\section{Footnote}

Reporting Checklist: The authors have completed the MDAR reporting checklist. Available at https://dx.doi. org/10.21037/tp-21-86

Data Sharing Statement: available at https://dx.doi. org/10.21037/tp-21-86

Conflicts of Interest: All authors have completed the ICMJE uniform disclosure form (available at https://dx.doi. org/10.21037/tp-21-86). The authors have no conflicts of interest to declare.

Ethical Statement: The authors are accountable for all aspects of the work in ensuring that questions related to the accuracy or integrity of any part of the work are appropriately investigated and resolved. The study was conducted in accordance with the Declaration of Helsinki (as revised in 2013). The study was approved by the Institutional Ethics Committee of the West China Second University Hospital of Sichuan University. Written informed consent was obtained from individual or guardian participants.

Open Access Statement: This is an Open Access article distributed in accordance with the Creative Commons Attribution-NonCommercial-NoDerivs 4.0 International License (CC BY-NC-ND 4.0), which permits the noncommercial replication and distribution of the article with the strict proviso that no changes or edits are made and the original work is properly cited (including links to both the formal publication through the relevant DOI and the license). See: https://creativecommons.org/licenses/by-nc-nd/4.0/.

\section{References}

1. Bonnet D, Dick JE. Human acute myeloid leukemia is organized as a hierarchy that originates from a primitive hematopoietic cell. Nat Med 1997;3:730-7.

2. Hope KJ, Jin L, Dick JE. Acute myeloid leukemia originates from a hierarchy of leukemic stem cell classes that differ in self-renewal capacity. Nat Immunol 2004;5:738-43.

3. Lapidot T, Sirard C, Vormoor J, et al. A cell initiating human acute myeloid leukaemia after transplantation into SCID mice. Nature 1994;367:645-8.

4. Reya T, Morrison SJ, Clarke MF, et al. Stem cells, cancer, and cancer stem cells. Nature 2001;414:105-11.

5. Brüne B, Dehne N, Grossmann N, et al. Redox control of inflammation in macrophages. Antioxid Redox Signal 2013;19:595-637.

6. Mantovani A, Sozzani S, Locati M, et al. Macrophage polarization: tumor-associated macrophages as a paradigm for polarized M2 mononuclear phagocytes. Trends Immunol 2002;23:549-55.

7. Theocharides AP, Jin L, Cheng PY, et al. Disruption of SIRP $\alpha$ signaling in macrophages eliminates human acute myeloid leukemia stem cells in xenografts. J Exp Med 2012;209:1883-99. 
8. Murdoch C, Giannoudis A, Lewis CE. Mechanisms regulating the recruitment of macrophages into hypoxic areas of tumors and other ischemic tissues. Blood 2004;104:2224-34.

9. Krishnan A, Hariharan R, Nair SA, et al. Fluoxetine mediates G0/G1 arrest by inducing functional inhibition of cyclin dependent kinase subunit (CKS)1. Biochem Pharmacol 2008;75:1924-34.

10. She M, Niu X, Chen X, et al. Resistance of leukemic stemlike cells in AML cell line KG1a to natural killer cellmediated cytotoxicity. Cancer Lett 2012;318:173-9.

11. Edwards JP, Zhang X, Frauwirth KA, et al. Biochemical and functional characterization of three activated macrophage populations. J Leukoc Biol 2006;80:1298-307.

12. Davis MJ, Tsang TM, Qiu Y, et al. Macrophage M1/M2 polarization dynamically adapts to changes in cytokine microenvironments in Cryptococcus neoformans infection. mBio 2013;4:e00264-13.

13. Tran J, Master Z, Yu JL, et al. A role for survivin in chemoresistance of endothelial cells mediated by VEGF. Proc Natl Acad Sci U S A 2002;99:4349-54.

14. Rivera CG, Mellberg S, Claesson-Welsh L, et al. Analysis of VEGF--a regulated gene expression in endothelial cells to identify genes linked to angiogenesis. PLoS One 2011;6:e24887.

15. Konopleva MY, Jordan CT. Leukemia stem cells and microenvironment: biology and therapeutic targeting. J Clin Oncol 2011;29:591-9.

16. Kornblau SM, Womble M, Qiu YH, et al. Simultaneous activation of multiple signal transduction pathways confers poor prognosis in acute myelogenous leukemia. Blood 2006;108:2358-65.

Cite this article as: Jiang M, He G, Wang J, Guo X, Zhao $\mathrm{Z}$, Gao J. Hypoxia induces inflammatory microenvironment by priming specific macrophage polarization and modifies LSC behaviour via VEGF-HIF1 $\alpha$ signalling. Transl Pediatr 2021;10(7):1792-1804. doi: 10.21037/tp-21-86
17. Chen EY, Mazure NM, Cooper JA, et al. Hypoxia activates a platelet-derived growth factor receptor/ phosphatidylinositol 3-kinase/Akt pathway that results in glycogen synthase kinase-3 inactivation. Cancer Res 2001;61:2429-33.

18. Vasseur S, Afzal S, Tardivel-Lacombe J, et al. DJ-1/PARK7 is an important mediator of hypoxia-induced cellular responses. Proc Natl Acad Sci U S A 2009;106:1111-6.

19. McLaren J, Prentice A, Charnock-Jones DS, et al. Vascular endothelial growth factor is produced by peritoneal fluid macrophages in endometriosis and is regulated by ovarian steroids. J Clin Invest 1996;98:482-9.

20. Kloepper J, Riedemann L, Amoozgar Z, et al. Ang-2/ VEGF bispecific antibody reprograms macrophages and resident microglia to anti-tumor phenotype and prolongs glioblastoma survival. Proc Natl Acad Sci U S A 2016;113:4476-81.

21. Gerber HP, Dixit V, Ferrara N. Vascular endothelial growth factor induces expression of the antiapoptotic proteins Bcl-2 and A1 in vascular endothelial cells. J Biol Chem 1998;273:13313-6.

22. Tran J, Rak J, Sheehan C, et al. Marked induction of the IAP family antiapoptotic proteins survivin and XIAP by VEGF in vascular endothelial cells. Biochem Biophys Res Commun 1999;264:781-8.

23. O'Connor DS, Schechner JS, Adida C, et al. Control of apoptosis during angiogenesis by survivin expression in endothelial cells. Am J Pathol 2000;156:393-8.

24. Mesri M, Morales-Ruiz M, Ackermann EJ, et al. Suppression of vascular endothelial growth factormediated endothelial cell protection by survivin targeting. Am J Pathol 2001;158:1757-65. 

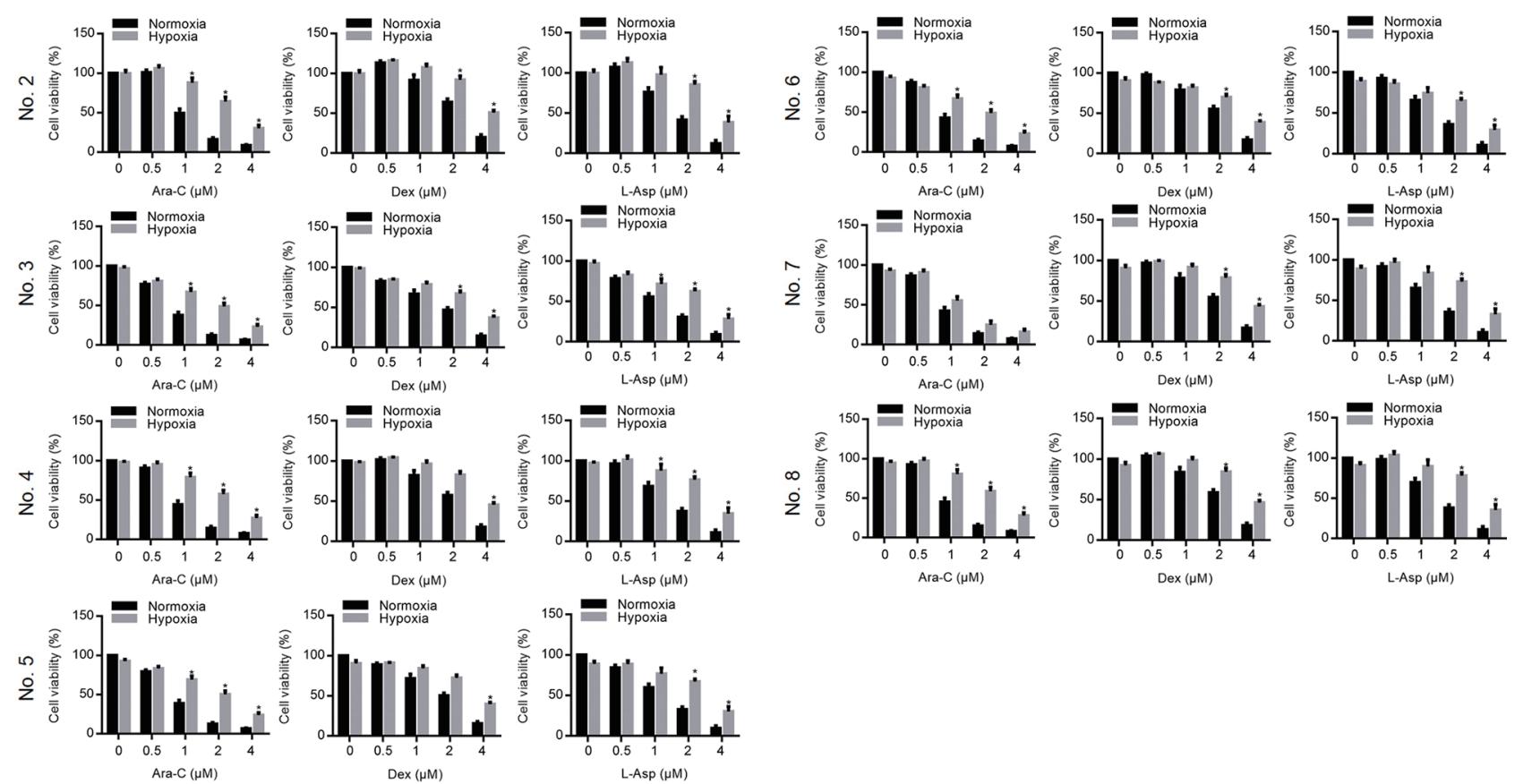

Figure S1 The chemosensitivity of clinical primary LSCs to Ara-c, Dex and L-Asp. CCK-8 assay was performed to detect chemosensitivity. ${ }^{*} \mathrm{P}<0.05$. vs. H-CM group. 